06

\title{
Влияние нановолокон оксида алюминия на физико-механические свойства минералонаполненного полиэтилена: экспериментальное исследование
}

\author{
(C) А.А. Куулар ${ }^{1}$, М.М. Симунин ${ }^{1-3}$, Т.В. Бермешев ${ }^{2}$, А.С. Воронин ${ }^{1,2}$, С.С. Добросмыслов ${ }^{1,2}, Ю^{\circ}$ В. Фадеев ${ }^{1}$, \\ М.С. Молокеев ${ }^{2,4}$, М.Н. Волочаев ${ }^{3,4}$, С.В. Хартов ${ }^{1}$ \\ ${ }^{1}$ Федеральный исследовательский центр „Красноярский научный центр СО РАН““, Красноярск, Россия \\ ${ }^{2}$ Сибирский федеральный университет, Красноярск, Россия \\ ${ }^{3}$ Сибирский университет науки и технологий им. акад. М.Ф. Решетнёва, Красноярск, Россия \\ ${ }^{4}$ Институт фозики им. Л.В. Киренского ФИЦ КНЦ СО РАН, Красноярск, Россия \\ E-mail: ayraana.kuular@mail.ru
}

Поступило в Редакцию 30 июня 2020г.

В окончательной редакции 17 августа 2020г.

Принято к публикации 6 сентября 2020г.

\begin{abstract}
Представлены результаты экспериментального исследования повышения физико-механических характеристик минералонаполненного полиэтилена (МНПЭ) посредством добавки высокоаспектных нановолокон оксида алюминия. Показано, что при весовой концентрации нановолокон оксида алюминия $0.1 \mathrm{wt} . \%$ предел прочности на растяжение повышается с $3.82 \pm 0.04$ до $6.70 \pm 0.07 \mathrm{MPa}$, а модуль Юнга увеличивается с $1.08 \pm 0.01$ до $1.38 \pm 0.01 \mathrm{GPa}$ (относительно МНПЭ). Композит МНПЭ/нановолокна $\mathrm{Al}_{2} \mathrm{O}_{3}$ можно описать моделью слабого адгезионного взаимодействия наполнителя с матрицей с высоким трением.
\end{abstract}

Ключевые слова: минералонаполненный полиэтилен, нановолокна оксида алюминия, физико-механические свойства, повышение прочности.

DOI: 10.21883/PJTF.2020.24.50419.18443

В настоящее время большое внимание исследователей по всему миру уделяется вопросам создания и исследования полимерных композитов, в которых удается получить более высокие физико-механические характеристики (модуль Юнга, предел прочности на разрыв и изгиб, микротвердость и т.д.) по сравнению с таковыми для чистой полимерной матрицы [1,2]. Во многих областях применения, таких как строительство, аэрокосмическая промышленность, автомобилестроение и медицина, использование композитных полимерных материалов является единственным возможным инженерным решением благодаря соотношениям прочности и массы композитов.

Развитие 3D-печати диктует необходимость интенсифицирования исследований в области полимерных композитов, в частности исследования и оптимизации параметров наполненных полимерных композиций, таких как минерало-, дерево- и металлонаполненные системы, для имитации свойств конкретных материалов. Также минералонаполненные полимеры применяются в производстве сандвич-панелей в строительстве и используются для облегчения конструкции. Наполненные полимерные композиты характеризуются высокой массовой долей наполнителя, находящейся в рамках 50-80\%. Высокая концентрация наполнителя и слабая межфазная адгезия матричного полимера к наполнителю ведет к охрупчиванию композита.

В работе рассматриваются получение и исследование физико-механических и морфологических свойств слож- носоставных композитов на основе матричного полиэтилена, наполненного минеральной смесью гидроксида магния и карбоната кальция (60 wt.\%), с малыми добавками высокодисперсных нановолокон оксида алюминия с массовой концентрацией 0.05, 0.1 и 0.5 wt.\%.

Композиты на основе минералонаполненного полиэтилена (МНПЭ) с добавкой нановолокон оксида алюминия были получены на одношнековом экструдере с многократным замешиванием (пять циклов экструдирования), за счет чего было достигнуто гомогенизированное распределение нановолокон оксида алюминия в МНПЭ. Экструзия включает следующие этапы: получение однородного расплава в экструдере, формование, охлаждение заготовки, натяжение и нарезка. При изготовлении композита как с добавкой нановолокон оксида алюминия, так и без нее образцы подвергались многократному экструдированию по одинаковой схеме. Таким образом, можно сделать вывод, что материал как с добавкой, так и без нее подвергся механической обработке единообразно.

Морфология и геометрические характеристики нановолокон оксида алюминия исследовались методом просвечивающей электронной микроскопии (ПЭМ) с помощью микроскопа Hitachi HT7700 (Japan). Рентгенограмма нановолокон была получена методом порошковой дифракции. Запись рентгенограммы осуществлялась при комнатной температуре с использованием порошкового дифрактометра Bruker D8 ADVANCE (Germany) $\left(\mathrm{Cu} K_{\alpha}\right.$-излучение) и линейного детектора VANTEC. Be- 

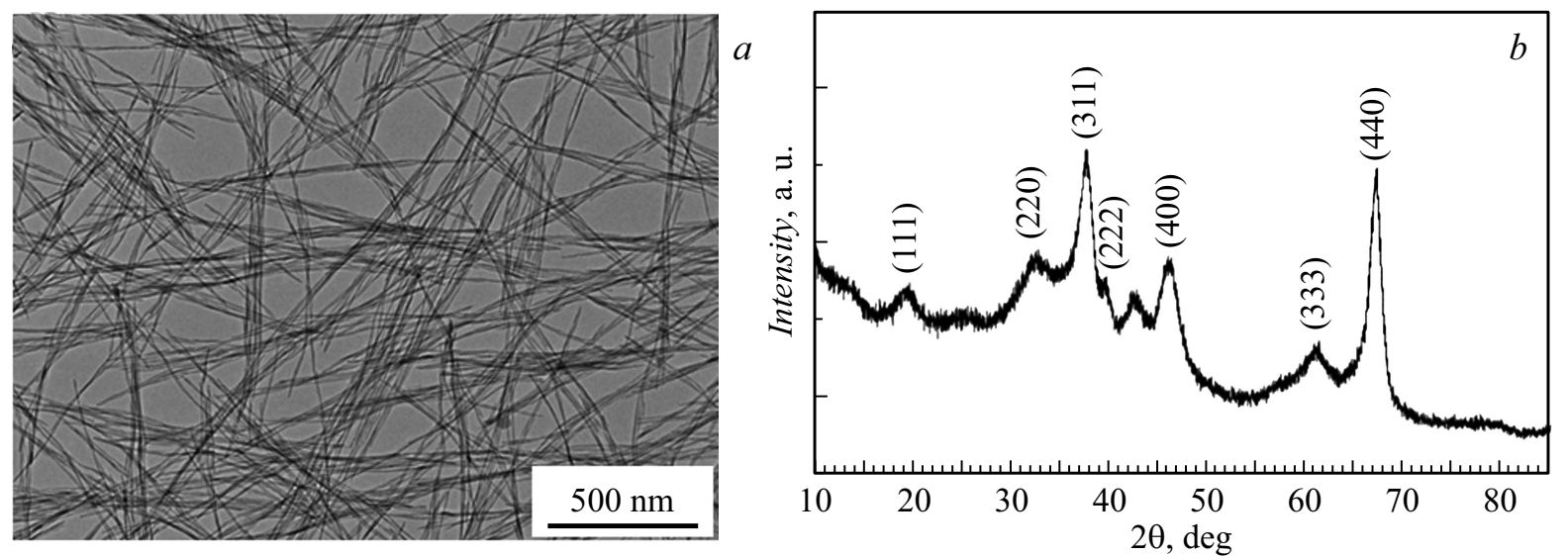

Рис. 1. ПЭМ-изображение (a) и порошковая дифрактограмма $(b)$ образца нановолокон оксида алюминия.

личина шага $2 \theta$ составляла $0.016^{\circ}$, а время счета $0.5 \mathrm{~s}$ на шаг. Морфологическое исследование композитов проводилось методом сканирующей электронной микроскопии (СЭМ) на микроскопе Hitachi TM3000 (Japan).

Экспериментальные исследования механических свойств, таких как предел прочности при растяжении и предел прочности на изгиб, проводились на универсальной разрывной машине LFM $20 \mathrm{kN}$, которая оснащена программным обеспечением DION pro. Механические свойства композитов изучались с помощью испытаний на растяжение и изгиб согласно ГОСТ 11262-2017 и ГОСТ 4648-2014. Исходя из упругой части кривой нагружения был вычислен модуль Юнга.

На рис. 1, а представлено ПЭМ-изображение нановолокон оксида алюминия. Согласно ПЭМ-изображению, средний диаметр нановолокон составляет $9 \pm 2 \mathrm{~nm}$. Диспергируемость используемых в работе нановолокон оксида алюминия выгодно отличается от таковой для наиболее популярного 1D-наполнителя - углеродных нанотрубок, имеющих склонность к запутыванию с образованием клубков, что существенно влияет на фрактальную размерность и физико-механические свойства композита [3].

Результаты исследования образца нановолокон $\mathrm{Al}_{2} \mathrm{O}_{3}$ методом порошковой дифракции представлены на рис. $1, b$. На дифрактограмме определяются пики, характерные, согласно карте № 77-396, для $\gamma-\mathrm{Al}_{2} \mathrm{O}_{3}$, а именно (111), (220), (311), (222), (400), (333), (440), которым соответствуют величины углов $2 \theta \sim 18.83,31.85,37.48$, $38.97,46.04,60.71,67.07^{\circ}$. Материал нановолокон принадлежит к кубической сингонии со структурой шпинели $\left(\mathrm{MgAl}_{2} \mathrm{O}_{4}\right)$, относящейся к пространственной группе $F d \overline{3} m$, с параметром решетки $a=b=c=7.906 \AA$. Уширение дифракционных пиков указывает на высокодисперсное состояние материала [4], что подтверждают результаты ПЭМ.

На рис. 2, а представлено СЭМ-изображение скола образца МНПЭ, в котором четко выделяются фазы $\mathrm{Mg}(\mathrm{OH})_{2}$ - крупные пластинчатые частицы размером до $10 \mu \mathrm{m}-$ и $\mathrm{CaCO}_{3}$ в виде сферических частиц размером $1-3 \mu \mathrm{m}$. На рис. $2, b$ представлено СЭМизображение образца с добавкой $0.5 \mathrm{wt} . \%$ нановолокон $\mathrm{Al}_{2} \mathrm{O}_{3}$. На изображении видна добавка нановолокон оксида алюминия в виде пучков волокон на фоне полимерной матрицы и частиц минерального наполнителя. В процессе экструзии и интенсивного перемешивания происходит измельчение нановолокон частицами $\mathrm{Mg}(\mathrm{OH})_{2}$ и $\mathrm{CaCO}_{3}$. Их размеры находятся на уровне $1-50 \mu \mathrm{m}$, тогда как размеры брикетов добавляемого в полимер материала нановолокон оксида алюминия имеют величину около $1 \mathrm{~cm}$.

В таблице приведены значения модуля Юнга для композитов МНПЭ/нановолокна $\mathrm{Al}_{2} \mathrm{O}_{3}$. МНПЭ имеет модуль Юнга $1.08 \pm 0.01 \mathrm{GPa}$, в то время как для ненаполненного полиэтилена высокой плотности он составляет порядка $0.80 \pm 0.01 \mathrm{GPa}$ [5]. Согласно данным таблицы, величина модуля Юнга для композита МНПЭ/нановолокна $\mathrm{Al}_{2} \mathrm{O}_{3}$ последовательно возрастает для всей исследуемой линейки образцов. Максимальная величина модуля Юнга для композита с добавкой нановолокон $\mathrm{Al}_{2} \mathrm{O}_{3} \quad 0.5 \mathrm{wt} \%$ составляет $1.38 \pm 0.01 \mathrm{GPa}$. Характер роста упругого отклика материала с ростом концентрации добавки указывает на то, что исследуемый в работе композит МНПЭ/нановолокна $\mathrm{Al}_{2} \mathrm{O}_{3}$ можно описать моделью слабого адгезионного взаимодействия наполнителя с матрицей с высоким трением. Данная модель характеризуется следующей зависимостью для увеличения модуля Юнга: $E_{c} / E_{m} \sim 1+\varphi$, где $\varphi-$ объемная доля наполнителя [6].

Следует отметить, что рост модуля Юнга также указывает на рост работы когезии полимерной матрицы в целом, т.е. нановолокна оксида алюминия упрочняют ее. Адгезионное взаимодействие между олефиновой матрицей, не имеющей полярных функциональных групп, и крупнодисперсными наполнителями слабое, имеющее в основном ван-дер-ваальсов характер. Оно пропорционально площади поверхности. Крупные частицы $\mathrm{Mg}(\mathrm{OH})_{2}$ и $\mathrm{CaCO}_{3}$ имеют достаточно низкую 


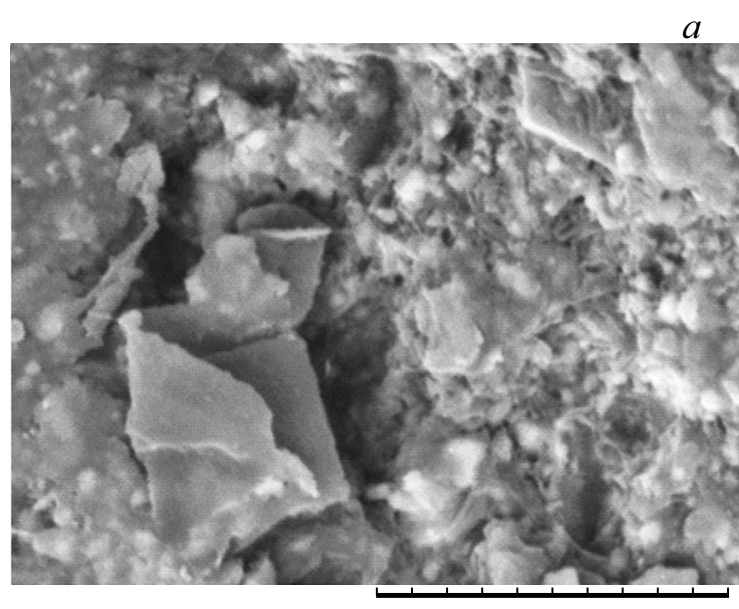

$20 \mu \mathrm{m}$

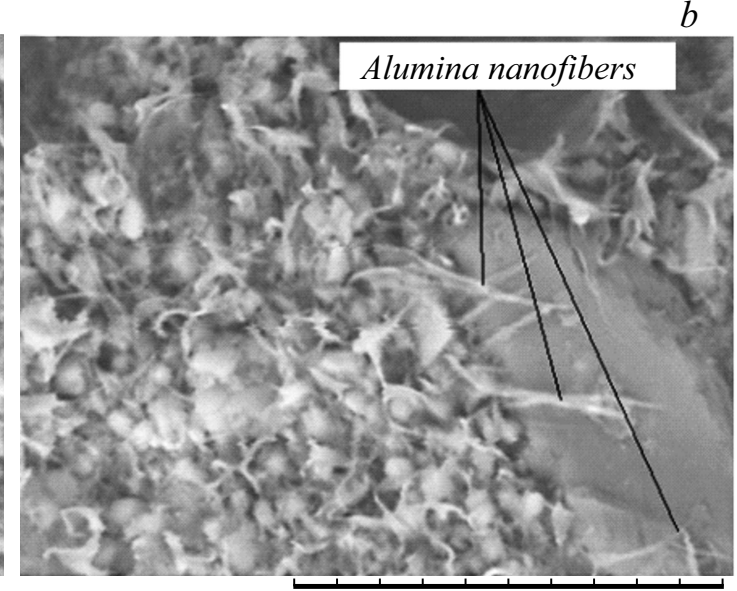

$20 \mu \mathrm{m}$

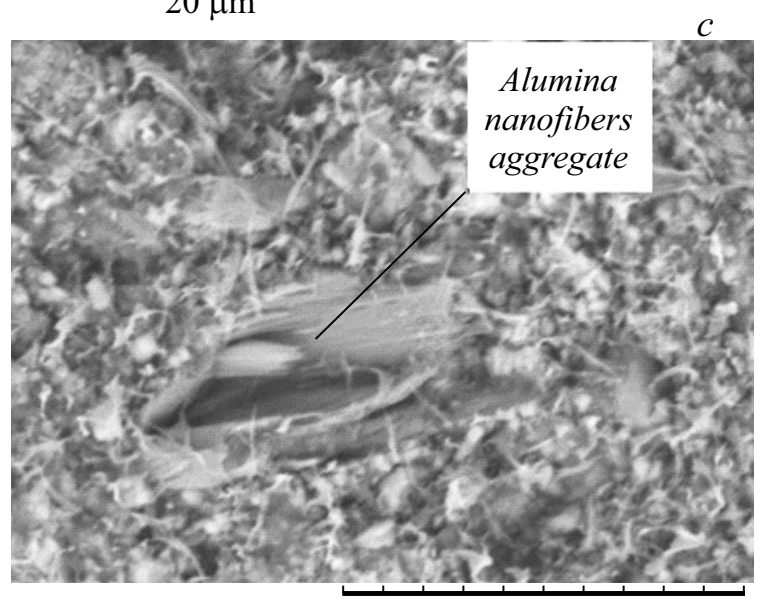

$30 \mu \mathrm{m}$

Рис. 2. Морфология МНПЭ без добавки нановолокон $(a)$, распределение нановолокон $\mathrm{Al}_{2} \mathrm{O}_{3}$ на сколе полимера $(b)$ и морфология агрегатов нановолокон $\mathrm{Al}_{2} \mathrm{O}_{3}(c)$.

Зависимость модуля Юнга и предела прочности на растяжение и изгиб для композитов МНПЭ/нановолокна $\mathrm{Al}_{2} \mathrm{O}_{3}$ при различной концентрации нановолокон

\begin{tabular}{l|c|c|c|c}
\hline \multicolumn{1}{c|}{ Параметр } & \multicolumn{4}{|c}{ Доля нановолокон $\mathrm{Al}_{2} \mathrm{O}_{3}$, wt.\% } \\
\cline { 2 - 5 } & 0 & 0.05 & 0.1 & 0.5 \\
\hline Модуль Юнга, GРа & $1.08 \pm 0.01$ & $1.19 \pm 0.01$ & $1.29 \pm 0.01$ & $1.38 \pm 0.01$ \\
Предел прочности на растяжение, MPa & $3.82 \pm 0.04$ & $6.21 \pm 0.06$ & $6.70 \pm 0.07$ & $6.05 \pm 0.06$ \\
Предел прочности на изгиб, МРa & $0.56 \pm 0.01$ & $0.50 \pm 0.01$ & $0.56 \pm 0.01$ & $0.52 \pm 0.01$
\end{tabular}

удельную поверхность. Ввиду этого предел прочности на растяжение для МНПЭ составляет $\sim 3.80 \pm 0.04 \mathrm{MPa}$ (см. таблицу). Добавка нановолокон $\mathrm{Al}_{2} \mathrm{O}_{3}$ в количестве $0.1 \mathrm{wt} . \%$ увеличивает предел прочности на растяжение материала до $\sim 6.70 \pm 0.07 \mathrm{MPa}$. При малых концентрациях (0.05 и 0.1 wt.\%) нановолокна свободно распределяются в матрице полиэтилена и формируют субструктуру, которая отвечает за рост прочности на разрыв. Дальнейшее падение прочности на разрыв с ростом концентрации (0.5 wt.\%) связано с тем, что выше порога перколяции нановолокон повышается вероят- ность образования агрегатов нановолокон $\mathrm{Al}_{2} \mathrm{O}_{3}$, которые являются центрами зарождения трещин и снижают прочность материала (рис. 2,c). Механизмы изменения предела прочности на растяжение композита напрямую связаны с особенностью субструктуры, формируемой минеральным наполнителем и нановолокнами оксида алюминия.

Предел прочности на изгиб для исследуемых композитов (см. таблицу) не демонстрирует существенных изменений, что, вероятно, связано с тем, что разрушение всегда происходит по границе раздела полимера и 
минерального наполнителя. Таким образом, нановолокна оксида алюминия, увеличивая работу когезии в полимерной матрице, не улучшают ее адгезию к минеральному наполнителю.

В работе изучено влияние добавки нановолокон оксида алюминия в МНПЭ. Это удобная модельная система, позволяющая транслировать результат на другие наполненные полимерные композиции. Показано, что добавление $0.1 \mathrm{wt} . \%$ нановолокон оксида алюминия в МНПЭ приводит к увеличению прочности на разрыв с $3.82 \pm 0.04$ до $6.70 \pm 0.07 \mathrm{MPa} \mathrm{и} \mathrm{увеличению} \mathrm{модуля}$ Юнга с $1.08 \pm 0.01$ до $1.38 \pm 0.01 \mathrm{GPa}$. Это обусловлено тем, что нановолокна оксида алюминия увеличивают работу когезии в полимерной матрице, но их взаимодействие с минеральным наполнителем не приводит к улучшению адгезии полимерной матрицы к минеральному наполнителю. Наблюдаемые результаты могут быть описаны моделью слабого адгезионного взаимодействия наполнителя с матрицей с высоким трением.

\section{Благодарности}

Исследования методом порошковой дифракции, просвечивающей и сканирующей электронной микроскопии выполнены на оборудовании Красноярского регионального центра коллективного пользования ФИЦ КНЦ СО PAH.

\section{Финансирование работы}

Работа выполнена в рамках государственного задания Минобрнауки России на выполнение коллективом научной лаборатории „Интеллектуальные материалы и структуры“ проекта „Разработка многофункциональных интеллектуальных материалов и структур на основе модифицированных полимерных композиционных материалов, способных функционировать в экстремальных условиях“ (номер темы FEFE-2020-0015).

\section{Конфликт интересов}

Авторы заявляют, что у них нет конфликта интересов.

\section{Список литературы}

[1] Hussain F., Hojjati M., Okamoto M., Gorga R.E. // J. Compos. Mater. 2006. V. 40. N 17. P. 1511-1575.

[2] Козлов Г.В. // УФН. 2015. Т. 185. № 1. С. 35-64.

[3] Микитаев А.К., Козлов Г.В. // ЖТФ. 2016. Т. 86. В. 10. C. 99-103.

[4] Гусев А.И., Курлов А.С. // Металлофизика и новейшие технологии. 2008. Т. 30. № 5. С. 679-694.

[5] https://www.engineeringtoolbox.com/young-modulusd_417.html

[6] Кнуняни Н.Н., Ляпунова М.А., Маневич Л.И., Ошмян В.Г., Шаулов А.Ю. // Механика композитных материалов. 1986. T. 22. № 2. C. 231-234. 